\title{
LEARNING ACROSS GENERATIONS AND CULTURES
}

by

\author{
JoAn Segal
}

\begin{abstract}
Interests in school library services and in library services to the disadvantaged ran through much of Anne Galler's professional work. This paper, a personal description of the author's work with the Sky City Community School Library (Acoma Pueblo, New Mexico), reflects these interests. Likewise, the fact that this work came about as part of an inter-generational and cross-cultural informal learning experience sponsored through an Elderhostel service project reflects Galler's personal interest in lifelong learning, and learning in retirement. The program included intensive learning about the Acoma Pueblo, about the education of indigenous peoples, and about the culture of the Acoma Indians. The author concludes that the experience highlighted the value of life-long learning.
\end{abstract}

\section{Introduction}

Degrees, certificates, and other mementos of educational milestones mark the learning achievements of our lives. The concept of continuous learning stresses that learning begins at birth and can (one could even say should) go on until one's last breath. Throughout life, learning continues in both formal and informal ways. While returning to the classroom for education in a new and different area of knowledge, or taking a continuing education class to update professional skills are now frequent occurrences, some learning can take place in situations far removed from traditional settings and need not be related to degrees or diplomas. On-the-job training and learning, mentoring, travel, book discussion groups, seminars on financial planning, participation in amateur choral and orchestral ensembles, clubs where presentations are made, and Bible-study groups are examples of informal learning experiences. This paper describes an inter-generational and cross-cultural informal learning experience, the opportunity for which came through an Elderhostel Service Project.

\section{Inter-Generational Learning}

One interesting kind of learning - often informal -- takes place across generations. Examples include retirees who voluntarily serve as tutors or museum docents, or who teach from their life experience in programs on business or professional development. Interestingly, there are many programs where children are the pro-active volunteers. Children visit nursing homes to share their enthusiasm with shut-in elders; they bring their pets into hospitals and retirement communities to offer their calming influence. In these settings, children learn about giving to those in need and about how it feels to do something that pleases others. The older people in these settings may come to appreciate that children are not only noisy and disruptive, but also caring human beings. In some educational experiences, older people and children participate jointly. Examples are travel programs designed for grandparents and grandchildren, and theatrical, musical, and dance presentations where young and old perform together.

\section{Cross-Cultural Learning}

While it is extremely difficult to understand another culture fully, there is a special difficulty when the learner is of a group that has historically mistreated members of the other culture. For many in the majority culture, there are limited opportunities for such learning. Often considerable discomfort may be experienced in finding out about historical injustices and deciding how to deal with this awareness in daily life. Although the decision to participate in learning within another culture carries a certain degree of personal risk (in terms of 
discomfort), to interact and learn from another culture comes with the great potential to open our minds and hearts with mutual benefit.

\section{Service as an Opportunity for Learning}

One kind of learning opportunity comes through service projects which bring the learner into a working relationship with members of another culture, so that the day-to-day experience of mutual engagement minimizes the potential for confrontation and discomfort and makes the most of the chance to learn from one another. Projects of this type are among those offered by Elderhostel.

\section{Elderhostel}

The Elderhostel concept originated in 1975, when a few hundred seniors (over age 55) began studying a variety of subjects on a handful of New England college campuses. By 1999 , almost 175,000 people took advantage of an impressive selection of short-term ( 1 - 4 - week) programs offering travel and learning experiences around the globe. In 1992, Elderhostel created its Service Projects to expand its offerings and to meet the needs of communities both in the U. S. and abroad. The goal of the Service Projects is to permit mature participants "to become part of a global community, dedicated to creating and maintaining a better world in which to live, learn, work, and play." Among other possibilities, these Service Projects include opportunities to teach English abroad, to work on environmental projects, and to assist with archeological research. The U. S. and Canada catalog for the summer of 2001 includes 25 different potential "service opportunities."

The 2001 Elderhostel Catalog offered an opportunity for a one-week-long project at the Acoma Pueblo near Albuquerque, New Mexico. This program was attractive to this author for several reasons. The description noted that one would work at the Sky City Community School, help children learn to read, read stories to students, and/or work in the school library. These opportunities seemed appropriate to a person with a background in story-telling and singing to children, and a long history of librarianship.

Between registration and the March 2001 start date of the program, staff members at the University of New Mexico in Albuquerque called the volunteers to plan specific details. They asked about each participant's experience and settled on certain tasks for each. Three of the volunteers would work in the library, some would do singing and story-telling with the children during their class's weekly library hour, and one would teach some simple tap dances. Preparation for the week of service included preparing some songs and stories for different grade levels, devising a simple set of dance steps that the children could learn, and collecting about a dozen pairs of tap shoes the children could wear to hear themselves tap dance.

The Elderhostel volunteers for this project consisted of nine women ranging in age from their late 60's to 89 ; the members came from New York, Michigan, Minnesota, Colorado and California and brought with them a variety of experience. Over the course of the week, they would share with the children knowledge of the Everglades, of polar bears waiting for ice floes to come into the Churchill, Canada, harbor so they could walk out to the islands in Hudson's Bay, of dolphins off Costa Rica, of the Holocaust and its horrors, of careers in writing children's books, editing and librarianship, as well as tap dancing.

The Elderhostel experience for this Service Project consisted of three parts: 1) the service component - work at the school; 2) the educational component - lectures on Native American culture; and 3) the cultural component - visits to related sites in the area.

\section{The Service Component}

The group arrived at the school on Monday morning to find the staff eagerly awaiting them. After meeting the principal and having a tour of the school building, six members of the group were assigned to classrooms and three to the library.

\section{The School Library}

The School Librarian, Ronni Chavez, a member of the local Grants community, was well prepared for her three volunteers. First, Ms. Chavez showed them around the library, located at the center of the school. While there are at present only about 4,000 volumes, a concerted effort is being made to accumulate donated materials and to select carefully for purchases to round out the collection. The materials are arranged by Dewey Decimal System on attractive shelving of a convenient height for the pupils. The reference collection is rudimentary and the librarian is paying special attention to enhancing it. Each classroom has a terminal with access to the Internet, and there is one workstation in the library that helps the staff answer questions. An interesting collection of materials in the Acoma language, including picture books, readers, 
and grammars occupies one section of the library. Fortunately, the school is blessed with a full-time substitute teacher who helps in the library on days or at times when she is not in a classroom.

The library has an online catalog that is available only on the library workstation. There are plans to add more stations. Picture books for the youngest children are on racks near the story-telling pit, an attractive corner of the large room where children sit on the semi-circular curved steps while the storyteller or reader is at their center. Audio-visual equipment is available to enhance such presentations. There is limited seating space in the library. The purchase of furniture, now underway, will permit more extensive use of the library for study, both as a "study hall" and as a resource for students to use in their research.

Each class has one hour of library time per week. The librarian selects appropriate programming, points out new books that have relevance, and assists the children in selecting and checking out materials. The reward for returning books on time is done on a classroom basis. If every child in the class has returned all the items that have been borrowed, all members of the class may borrow two books, rather than one, etc. until the class has reached five titles per student. The 5-book limit was set at the request of the teachers, who generously assist in tracking overdues.

The librarian introduced a program in which staff members may buy books from a monthly display set up by a library vendor. Not only are the books sold at a discount, but also the library receives a free book for every five purchased by staff members. During the week the Elderhostel group was there, there were picture books, a gardening encyclopedia, a well-illustrated new cookbook, and a travel book with colored photos of Ireland among those displayed.

The school's "Character Counts" program emphasizes values considered important. The six "pillars" of the program (they are mounted on the cafeteria wall) are: Trustworthiness, Responsibility, Respect, Fairness, Caring, and Citizenship. The librarian works on relating each of these "pillars" to the library. For instance, "The Library is a place where I can practice good character and where I can learn about trustworthiness, responsibility, respect, fairness, caring, and citizenship through my reading." One volunteer helped with this effort.

\section{Library Projects}

Ms. Chavez prepared for the volunteers' arrival by identifying several specific projects to be carried out. These pro- jects included: 1) creating a "map wall" in one corner of the library; 2) assigning reading and interest level to a collection of books used in the school's intensive reading program; 3) making presentations to the classes as they came to the library for their weekly "library hour"; and, 4) carrying out an inventory of the Acoma language materials.

1) The first assignment for the library volunteers was to complete the creation of a "map wall" in one corner of the library. This involved learning to laminate maps, making legends, creating a large sign to identify the area, and mounting all of these on the walls in the corner of the library. This project was completed by week's end. It gave a focus to the corner, where maps and atlases are located. The design integrated postcards received by the school from various parts of the world, linking them to their geographic location by means of a ribbon connecting the card to the spot on the map from which it came.

2) The (K-8) school emphasized reading at every level by subscribing to a program called "Success for All," designed to improve reading skills. Every child in the school participated daily in reading activities from 8 to 9:30 a.m. A special collection of reading materials supported this program and the Elderhostel library volunteers were asked to identify and label each book in the collection as to interest and reading level. (For upper-grade students with low reading level, it is especially important to have materials that they are able to read, but which are not limited in interest to the very young.) For this purpose, the librarian provided a vendor's CD-ROM database that included interest and reading levels. If the title was not in the database, one of the members of the group with experience in educational publishing was able to provide the needed information. The Elderhostel volunteers completed this project in less than a week.

3) From the first day, classes coming in for their weekly library hour were turned over to one volunteer for storytelling. For the kindergarten and lower grade classes, she sang and shared library books that were new to them. The experience with the children was extraordinary. In the library, they eagerly learned new song-stories, participated actively in singing along, and even sang two songs in the Acoma language for her. The children in the middle and upper grades showed a great interest in learning to tap dance. The volunteer taught a simple routine. The lesson integrated the history of tap dance as a means of communicating among an enslaved people denied the right to their native culture. She emphasized meter and rhythm as musical elements as important as melody. And she choreographed a routine which, though simple, was based on the $\mathrm{Zia}$, a traditional Pueblo design. The 
dancing was very popular with the children and their teachers.

4) The inventory of the Acoma collection was not completed, at least in part due to an unexpected additional task. The volunteers were needed to complete the purchase of library materials when the purchase deadline was unexpectedly moved up. 2

\section{The Educational Component}

At the very beginning of the week, group members were introduced to the program coordinator, a woman of Navajo and Acoma heritage, who remained with them throughout the week. She served as driver and constant companion, a trustworthy source of information, and provider of both informal and more formal education about Indian traditions, history, kinship ties, and spiritual beliefs. Not only did she present three hour-long lectures in the evenings, but was available all the time, open to all kinds of questions, and willing to provide answers from her personal perspective as well as from her traditional background.

\section{Acoma Pueblo}

The Acoma people are one of 19 "pueblo" communities in New Mexico. Each of the communities has as its basic location a "pueblo," that is, a set of buildings built in layers, one atop the other. The Acoma Pueblo, now inhabited only part of the year, is often referred to as "Sky City," because it is situated on a high plateau, which protected it from invasion. Each of the pueblo communities is slightly different from the others, but they all share a long history, similar kinship ties and spiritual beliefs, and a history of subjugation to the Spanish who invaded the area in the 16th Century.

Ties of kinship are very complicated and very important. They determine who leads the community, who has a say in family decisions, and how power is wielded and order maintained. Community decisions are made, not according to the democratic principle that the majority rules, but according to a kind of consensus, where much effort goes into making the final decision acceptable to all. In cases of infraction of rules, the decision about the appropriate punishment is a matter of serious community concern. A solution to the problem is sought that will serve to re-integrate the offender into the community in the best possible manner. Ceremony and ritual play an important part in the culture and nature is the supreme power. The Acoma are a matrilineal people, with the lines of descent traced through the mother and the female line. The newly-married couple moves into the wife's community and the husband gradually becomes part of this community.

Like other pueblo communities, the Acoma have been affected by the world that surrounds them. Many of the young people have left the local area for cities and have abandoned their traditional values. Although there are still individuals, even young people, who remain traditional in their outlook and lives, many have come to some kind of compromise with the culture of the "outside" world and some have moved completely into that "modern" culture.

\section{Education of Indigenous People}

One of the coordinator's early lectures concerned the education of indigenous people, including the Acoma. From the middle of the 19th Century, the U. S. Government has provided education for Native Americans. ${ }^{1}$ The purpose of this education was to assimilate the people into the mainstream of European Americans as quickly as possible. Under the direction of the Department of the Interior, and specif $\mathrm{i}$ cally, the Bureau of Indian Affairs (BIA) Indian children were forcibly removed from their homes and taken to boarding schools, where they were forbidden (under threat of serious punishment) to speak their language or practice their religion. Many of the schools were run by church groups, some Catholic, some Protestant. The children were taught Christianity, the importance of European-American concepts of cleanliness, time, the rule of the majority, and, implicitly, the superiority of the White race. Teaching methods were severe, with beatings, isolation, and scorn seen as necessary techniques to "civilize" the children so they could become productive members of American society.

By about 1924, the effects of this educational system could be seen in the complete breakdown of the family structure of the American Indians. Children raised in the boarding schools had no idea of how to be parents; they were alienated from their own parents and had been raised in an environment totally lacking in the love and care they needed to raise children themselves. They lacked any sense of cohesiveness with each other and had developed a strong sense of self-hatred. At about that time, "underground" movements to maintain traditional ceremonies led.to increased control by the BIA. But the native people began to seek a fairer educational system. This led to the establishment of day schools, which, while they did not greatly change the strategy of assimilation nor improve the punitive nature of the educational experience, did at least allow the children to live with their parents and to have some 
exposure to their own culture. Nonetheless, the traditions of the Native Peoples were ignored with regard to land use, irrigation, and farming methods. And there were limits to education for Indians. They were encouraged to learn a vocation, whether or not they qualified for higher education. Eventually, with community pressure, these barriers began to erode. Numerous indigenous students now attend university in their states, sometimes on scholarships, or they may attend one of the Indian tribal colleges.

In 1968, at the height of the American Indian Movement, and before it was taken over by violent factions, communities began to rebel. Through the next decade or more, there was increased empowerment of Indian communities. By 1985, a movement toward Community Schools had successfully emerged.

Lest there be any misunderstanding about these schools, it is good to remember that they are still federally funded and therefore not free of federal control. The federal government pays the staff members directly and provides other support as monies become available and in the form of actual purchasing rather than of fund transfers. The funding for purchasing can be erratic. ${ }^{2}$

The difference between the traditional BIA boarding schools of the early 20th century and the (Acoma) Sky City Community School is extraordinary. Although there is a federal curriculum that is set, this is done with some input from the community. A majority of the teachers in the school are members of the Acoma community or other, neighboring native peoples. The library contains materials that allow children to find role models among their own people. The school provides employment for a number of well-educated community members. And the children are well-cared-for, fed lunches prepared on the premises by members of the community, taught in classes of small size (typically fewer than 20 in a class) by teachers of their own community who attend to their intellectual growth, and who take into account their physical, emotional, and psychological problems.

The current movement is toward the establishment of contract schools, which will still be federally funded, but where the curriculum will be free of federal input, more community-oriented, and where funds will actually be placed in the bank for the schools. It should be stated that the Native Communities are always af raid of the complete withdrawal of federal support, fearing that Indian education, if left to the states in which their communities are located, would decline seriously. ${ }^{3}$

\section{The Cultural Component}

On Monday afternoon, the program provided an opportunity to visit "Sky City," the high plateau where the Acomas have lived for hundreds of years. Guides at the site shared information about the pueblo, about some of the traditions of the people, and about their life. The participants walked around the pueblo, viewing the nature of the buildings, open spaces, and learning some of the history of the Acoma Pueblo.

Another half day, on Friday, offered participants the chance to visit two major museums. The Indian Pueblo Cultural Center emphasizes the culture of the 19 pueblos, each with its artistic specialties and unique history. At the Albuquerque Museum, the accent is more on the Spanish presence in the area and on the Western movement of the European Americans, including the founding of the city by the Spaniards and its subsequent role in the development of the State of New Mexico.

On Saturday, a tour of Santa Fe was offered. There, participants could view museums of Native American, Spanish, and modern art and history, see the layout of the city around its plaza, enjoy typical food of the area, and see the State Government buildings, built in the Spanish Colonial Style.

\section{High Points of the Project Experience}

The preparedness of the librarian and other teachers and their knowledge of how to use volunteers successfully yielded a very high quality experience. The Elderhostel volunteers all felt they had done useful work and had really been able to make a valuable contribution to the school and the community.

In the classrooms, the children were extremely interested in the Elderhostel volunteers and what they had to say. The Elderhostel group members repeatedly remarked on the children's behavior and attitude: respectful but affectionate, extremely polite, and attentive to all that was new.

A birthday party held for the oldest volunteer, who celebrated her 89th birthday during the week, exemplified the personal nature of the experience. It was a double party, since one of the children turned 11 on the same day. It was therefore, the group was told, a one-hundredth birthday party! There were cake and soft drinks to celebrate the occasion, to which all the volunteers were invited.

The accessibility of staff members was surprising. A teacher taught one of the volunteers the Acoma lullaby the children had sung. The principal made himself available for an interview about the school and community. The coordinator was always willing to answer questions. The librarian and reading teacher, as well as the principal and the coordinator, all agreed to review this paper for accuracy. 


\section{Conclusions}

This experience highlighted the value of life-long learning. For all the volunteers, at an age when many would consider them outside the realm of usefulness or ability to learn, a valuable opportunity allowed them to teach and to learn in a constructive manner.

All felt the importance of service; the notion of giving back to the world something of value that would repay some of the favors received during relatively long lives. All enjoyed the feeling of being able to make a contribution to this particular community, whose needs are great, but whose determination to succeed is outstanding.

The specific learning - about Native peoples, their traditions, their culture, and their various ways of adapting to the western world, was integrated marvelously into the volunteers' daily lives. Respect for these traditions will always be of priority for these Elderhostelers.

While each volunteer made small contributions: creating a map wall, ordering library materials, labeling a reading collection, sharing song-stories with children, teaching them to tap dance, working with teachers in classrooms, giving talks about polar bears, alligators, or dolphins, all came away feeling they had been both givers and receivers.

A goal of this paper is to encourage others to continue learning and service: to find, to create, or to realize opportunities for ourselves and others in order to be useful all the way to the end of life.

\section{Bibliography}

Cooper, M. L. (1999). Indian School: Teaching the White Man's Ways. New York: Clarion Books.

Carter, F. (1976). The Education of Little Tree. Albuquerque, NM: University of New Mexico Press.

Hirschfelder, A. B. (1999). American Indian Stereotypes in the World of Children: a Reader and Bibliography (2nd ed.). Lanham, MD: Scarecrow Press.

Meyers, H. B. (1999). Reservations. Niwot, CO: University Press of Colorado.

Szusz, M. (1974). Education of the Indian: the Road to SelfDetermination. Albuquerque, NM: University of New Mexico Press.

\section{Notes}

1. From the time of Columbus' voyages, the indigenous people were known as Indians, then as American Indians. In the 1950's and 1960's, with the growth of the American Indian Movement, the designation Native Americans became more acceptable to the group. In the 1980's and 1990's, various "tribes" or nations were identified as different from each other and by the 1990's, the designation First Nations began to be used, especially in the Eastern part of the U. S. However, the term Indigenous People is still acceptable. At this time, according to the coordinator, any of these terms can be used, although there are some people who strongly prefer one or the other. This paper uses all of the terms as a way of acknowledging them as acceptable to some, if not all, indigenous people.

2. The erratic nature of federal funding became abundantly clear to the library volunteers when they arrived at the school library on Wednesday morning of the week-long volunteer session. They found the librarian eagerly awaiting them to hold a "Staff Meeting" to discuss an urgent matter. The principal had called the librarian in on Tuesday evening after school hours to say that she was to be allowed to buy $\$ 12,000$ worth of library materials, but that she had to spend the money by that Friday afternoon and could use no more than two vendors. In anticipation of the release of funds, she had already entered some $\$ 6,000$ worth of orders into her vendor-supplied order system, where they were awaiting the approval of the business manager. However, she needed help to identify other items from flyers, recommended lists, and catalogs, to check the on-line catalog to avoid duplication, and to place the orders. The volunteers went to work looking through publishers' catalogs, searching the on-line catalog, entering orders into the vendor database (mentioned earlier) and passing titles not found there on to a local vendor representative who showed up late in the afternoons with his laptop computer to place the remaining orders.

3. It is possible for Native children to attend the public schools in their states. Only a few from the Acoma Pueblo do so. Many Acoma students still attend the local Roman Catholic parochial school.

JoAn Segal is a member of the Education Libraries Editorial Committee, and President of Vintage Ventures, a consulting firm. Among other things, JoAn has been the Executive Director of the Association of College \& Research Libraries, Associate Executive Director of the American Library Association, and President of the Special Libraries Association Rocky Mountain Chapter. Email: jsegalvv@earthlink.net 